OPEN ACCESS

Edited by:

Sofie Struyf,

KU Leuven, Belgium

Reviewed by: Ahmed M. Abu El-Asrar, King Saud University College of Medicine, Saudi Arabia Undurti Narasimha Das, UND Life Sciences LLC, United States

${ }^{*}$ Correspondence: Dirk Bauer dirk.bauer@uveitis-zentrum.de

tShared first authorship.

Specialty section:

This article was submitted to

Cytokines and Soluble

Mediators in Immunity,

a section of the journal

Frontiers in Immunology

Received: 07 February 2018

Accepted: 22 March 2018

Published: 05 April 2018

Citation:

Bauer D, Kasper M, Walscheid K, Koch JM, Müther PS, Kirchhof B, Heiligenhaus A and Heinz C (2018)

Multiplex Cytokine Analysis of Aqueous Humor in Juvenile Idiopathic Arthritis-Associated Anterior Uveitis With or Without Secondary Glaucoma.

Front. Immunol. 9:708. doi: 10.3389/fimmu.2018.00708

\section{Multiplex Cytokine Analysis of Aqueous Humor in Juvenile Idiopathic Arthritis-Associated Anterior Uveitis With or Without Secondary Glaucoma}

\author{
Dirk Bauer $^{1 *+}$, Maren Kasper ${ }^{1 \dagger}$, Karoline Walscheid ${ }^{1}$, Jörg M. Koch ${ }^{1}$, Philipp S. Müther ${ }^{2}$, \\ Bernd Kirchhof ${ }^{2}$, Arnd Heiligenhaus ${ }^{1,3}$ and Carsten Heinz ${ }^{1,3}$
}

${ }^{1}$ Department of Ophthalmology and Ophtha-Laboratory at St. Franziskus-Hospital Münster, Münster, Germany, ${ }^{2}$ Center for Ophthalmology, University of Cologne, Cologne, Germany, ${ }^{3}$ Center for Ophthalmology, University of Duisburg-Essen, Essen, Germany

Patients with juvenile idiopathic arthritis often develop chronic anterior uveitis (JIAU). JIAU patients possess a particularly high risk for developing secondary glaucoma when inflammatory inactivity has been achieved. By using multiplex bead assay analysis, we assessed levels of pro- and anti-inflammatory cytokines, chemokines, or metalloproteinases in the aqueous humor (AH) of patients with clinically inactive JIAU with (JIAUwG) or without secondary glaucoma (JIAUwOG), or from patients with senile cataract as controls. Laser-flare photometry analysis prior to surgery showed no significant differences between JIAUwG or JIAUwoG. Compared with the control group, levels of interleukin-8, matrix metalloproteinase-2, $-3,-9$, serum amyloid $A(S A A)$, transforming growth factor beta-1, $-2,-3$ (TGF $\beta-1,-2,-3)$, and tumor necrosis factor-alpha in the $A H$ were significantly higher in patients with clinically inactive JIAUwG or JIAUwoG. Samples from JIAwoG patients displayed significantly higher levels of SAA $(P<0.0116)$ than JIAUwG patients. JIAUwG patients showed an increased level of TGF $\beta$-2 in AH samples compared with JIAUwoG $(P<0.0009)$. These molecules may contribute to the clinical development of glaucoma in patients with JIAU.

\footnotetext{
Keywords: juvenile idiopathic arthritis-associated anterior uveitis, secondary glaucoma, intraocular pressure, multiplex bead assay analysis, aqueous humor
}

\section{INTRODUCTION}

Approximately $11-13 \%$ of patients with juvenile idiopathic arthritis eventually develop uveitis (JIAU), too, typically as chronic anterior uveitis with insidious onset, in the absence of redness or pain. Risk factors for developing uveitis include the presence of anti-nuclear antibodies, oligoarthritis subtype, and early onset of the disease (1). Early onset of uveitis poses a particularly high risk for developing sight-threatening complications, such as synechiae, cataract, glaucoma, and macular edema $(2,3)$. To prevent such complications, the main goals in treating juvenile idiopathic arthritis (JIA) children include early recognition of uveitis, achieving inflammatory inactivity, preserving vision, and avoiding development of further complications. 
Topical treatment with corticosteroids is the first-line therapy, but it may promote elevated intraocular pressure (IOP) and cataract development. Systemic medication with methotrexate, adalimumab, and other disease-modifying anti-rheumatic drugs (DMARDs) can be used if the topical treatment is ineffective or for chronic disease. Uveitis patients have an increased risk for elevated IOP and uveitic glaucoma (UG), which might be induced by the inflammatory disease, but may also result from corticosteroids given as the first treatment approach to reduce ocular inflammation (4). Reported incidence rates of glaucoma in patients with JIAU are up to 38\% (5). Mostly, the IOP first increases when inflammatory activity has been eliminated, possibly due to reduced uveoscleral outflow (6). Patients with UG frequently develop very high-IOP values, with peaks of IOP and varying responses to topical anti-glaucomatous drugs, so that about one-third of adult patients and nearly two-thirds of pediatric patients need surgery (7). Many investigators believe that secondary open-angle glaucoma develops as a result of chronic changes to the outflow pathway of the trabecular meshwork (TM). Changes to the TM include deposition of extracellular matrix (ECM), different composition of ECM protein, and loss of trabecular endothelial cells, eventually leading to reduced phagocytosis and altered protein cleavage $(4,8)$. Another often described, but not clearly confirmed explanation for increasing IOP is mechanical obstruction of the outflow pathway by cells and debris $(4,8,9)$. Local immune responses may differ in JIAU patients with (JIAUwG) or without glaucoma (JIAUwoG), thereby mediating different outflow rates of the TM. It has been shown previously that active inflammation may result in increased uveoscleral outflow rates and reduced aqueous humor (AH) production (10).

Such local immune responses may be controlled by proinflammatory and anti-inflammatory cytokines, which can be secreted by immune cells and certain other cell types to regulate inflammation. Proinflammatory cytokines are predominantly produced by helper $\mathrm{T}$ cell and macrophages to upregulate inflammatory reactions (11). Therapies against inflammatory diseases often involves monoclonal antibodies targeting proinflammatory cytokines or their receptors. Proinflammatory cytokines [e.g., tumor necrosis factor-alpha (TNF- $\alpha$ ) or IL-1 $\beta$ ] may activate proforms of metalloproteinases (MMP) which are known to participate in the degradation of ECM and in the regulation of IOP (12). Anti-inflammatory cytokines like transforming growth factor beta (TGF- $\beta$ ) often have both pro-and anti-inflammatory effects. TGF- $\beta$ may convert an active site of inflammation into one dominated by resolution and repair (13). TGF- $\beta$ often exhibits disparate effects with immune-enhancing activity in local tissues and immune-suppressive function in the systemic circulation. TGF- $\beta 1$ and TGF- $\beta 2$ may increase ECM production in the anterior chamber and also inhibit the degradation of existing ECM, e.g., by downregulating MMPs $(14,15)$.

We hypothesized that altered outflow rates might be reflected by alterations in the MMP, interleukin (IL)-8, and TGF $\beta$ pathways. Therefore, measuring cytokine concentrations in the $\mathrm{AH}$ of JIAU patients with and without glaucoma could increase our knowledge of the local pathogenetic processes and may help to explain why some patients with JIAU develop glaucoma and others do not. The multiplex bead immune assay technique allows the simultaneous detection of multiple cytokines even from small clinical samples, as shown previously in patients with uveitis (16-18), branch retinal vein occlusion (19), or primary open-angle glaucoma (POAG) (20). In the present study we used this method to investigate the cytokine profile in patients with clinically inactive JIAU with or without glaucoma.

\section{MATERIALS AND METHODS}

\section{Subjects}

The study design complies with the standards put forth by the Declaration of Helsinki. The study was approved by the local ethics committee. All subjects provided written informed consent for $\mathrm{AH}$ collection during independently planned surgery. For underaged JIAU patients, written informed consent was obtained from the patients' parents.

Uveitis was classified according to the recommendations put forth by the international uveitis study group (IUSG), under consideration of the recent modifications $(21,22)$. Laser-flare photometric measurements taken at the final visit before surgery were performed according to previous studies (23-25) using the KOWA FM-500 device (Kowa Company, Electronics and Optics Division, Tokyo, Japan).

Diagnosis and treatment of JIAU followed the German national recommendations for management of disease (26). All patients fulfilled the International League of Associations for Rheumatology (ILAR) criteria for JIA diagnosis (27) and were classified accordingly. Glaucoma diagnosis was established when visual field defects or optic neuropathy were observed. IOP could not be controlled in any of the eyes in the JIAUwG group despite maximally tolerable topical or systemic IOP-lowering therapy or the optic nerve had deteriorated despite apparently normal IOP values. Therefore, standard trabeculectomy to lower IOP was performed in all eyes of the JIAUwG group, and aqueous taps were taken at the beginning. Eyes with JIAUwoG showed no changes at the optic nerve and had not received any topical or systemic IOP-lowering medication at any time during the previous clinical course. In JIAUwoG patients, IOP was never measured above $21 \mathrm{mmHg}$. Aqueous taps in the JIAUwoG group were taken at the beginning of routine cataract extraction. As a control group, patients undergoing routine surgery for senile cataract were included.

For all groups, suspicion of steroid-induced ocular hypertension constituted an exclusion criterion. None of the JIAU eyes had active inflammation, as defined by anterior chamber (AC) cells $\geq 0$ during the 3 months prior to $\mathrm{AH}$ collection, and all had been treated $5 \times$ daily with prednisolone acetate $1 \%$ for one week prior to surgery. In the control group, any history of systemic or eye inflammation represented an exclusion criterion. Only one eye of an individual patient was included in the study in all groups.

\section{AH Collection}

Aqueous humor samples (100 to $200 \mu \mathrm{l}$ ) were collected at the beginning of the surgery through limbal paracentesis using a $0.5-\mathrm{ml}$ syringe with a 30-gauge needle (BD Hamburg, Germany). Care 
was taken to prevent contamination with blood or intraocular tissue. All samples were immediately frozen and stored at $-80^{\circ} \mathrm{C}$ until analysis.

\section{Multiplex Bead Assay}

Concentrations of IL-8, monocyte chemoattractant protein-1 (MCP-1), matrix metalloproteinases-1, -2, -3, -9 (MMP-1, -2, $-3,-9)$, serum amyloid A (SAA), TGF $\beta-1,-2,-3$, and TNF- $\alpha$ were measured by multiplex bead assay analysis (Luminex ${ }^{\circledR}$ Performance Assay TGF $\beta$ Multiplex Kit R\&D Systems Abingdon UK; Procarta ${ }^{\circledR}$ Immunoassay Affymetrix, Santa Clara US) according to the manufacturer's instructions. Samples were analyzed with LUMINEX ${ }^{\circledR} 100 / 200^{\mathrm{TM}}$ using the Luminex xPonent software (Luminex, USA).

\section{Statistical Analysis}

Statistical analysis was performed using MedCalc statistical software 10.0.1.0 (Marikerke, Belgium). For analysis of normally distributed data, Student's $t$-test or ANOVA was applied. For categorical values, $\chi^{2}$ or Fisher's Exact test were used. $P \leq 0.05$ was considered as statistically significant. For multiple comparisons, Bonferroni correction was applied and $P \leq 0.0045$ was considered as statistically significant. Correlations between different cytokine concentrations, correlation between cytokine concentrations and age, duration of uveitis, and non-invasive laser flare were calculated using Spearmans's correlations test. Odds ratios (ORs) for the effect of all cyctokines and clinical parameters were calculated using multivariate logistic regression models with backward variable selection.

\section{RESULTS}

\section{Demographic Data}

Overall, 30 JIAU patients, 15 JIAU subjects without glaucoma (JIAUwoG) (average 15.1 years at AH collection) and another 15 JIAU subjects with glaucoma (JIAUwG) (average 13.1 years at $\mathrm{AH}$ collection), were included. Additionally, 24 subjects with senile cataract (average 75.5 years at AH collection) were used as controls. The demographic data of the subjects, including number of patients, age, duration of uveitis, lens status, and most recent laser-flare values, are summarized in Table 1.

Age of JIAUwG and JIAUwoG patients did not significantly differ $(P=0.5)$; however, both JIAU groups were significantly younger than the control group with senile cataract $(P<0.0001)$. Furthermore, disease duration of JIAU (time from onset to the date of surgery) in patients without or with glaucoma was not significantly different $(P=0.37)$.

Six JIAUwG patients had received topical prostaglandins (Latanoprost or Bimatoprost) until 2 weeks before glaucoma surgery. Six of 15 JIAUwoG subjects had received steroids systemically, while this was the case in only 2 of 15 JIAUwG patients (Table 1). Of both JIAU groups, 13 of 15 subjects had received conventional synthetic disease-modifying anti-rheumatic drug (csDMARD; methotrexate, cyclosporine A, or azathioprine). Three of 15 subjects with JIAUwoG and 2 of 15 subjects with JIAUwG had received biological disease-modifying anti-rheumatic drug (bDMARD; adalimumab, infliximab, or tocilizumab).
TABLE 1 | Demographic data of patients, treatment, and non-invasive laser-flare measurements.

\begin{tabular}{|c|c|c|c|c|}
\hline & C & JIAUwoG & JIAUwG & $P$-value \\
\hline Number of eyes & 24 & 15 & 15 & \\
\hline Age (years; mean \pm SD) & $75.5 \pm 9.1$ & $15.1 \pm 11.5$ & $13.1 \pm 3.4$ & $<0.001^{*}$ \\
\hline $\begin{array}{l}\text { Duration of uveitis (years, } \\
\text { mean } \pm S D \text { ) }\end{array}$ & n.a. & $5.6 \pm 4.5$ & $6.9 \pm 3.1$ & $0.37^{\#}$ \\
\hline Lens status & n.a. & 15 phakic & $\begin{array}{c}9 \text { phakic, } 3 \\
\text { PC IOL, } 3 \\
\text { aphakic }\end{array}$ & $0.023^{+}$ \\
\hline Posterior synechiae (eyes) & n.a. & 13 & 6 & $0.03^{+}$ \\
\hline Systemic corticosteroids & n.a. & 6 & 2 & $0.21^{+}$ \\
\hline csDMARD & n.a. & 13 & 13 & $1^{+}$ \\
\hline bDMARD & n.a. & 3 & 2 & $1^{+}$ \\
\hline $\begin{array}{l}\text { Non-invasive laser-flare } \\
\text { photometric analysis } \\
\text { (KOWA LF-500) (photons/ } \\
\text { ms, mean } \pm \text { SD) }\end{array}$ & n.a. & $110.3 \pm 40.8$ & $65.5 \pm 15.3$ & $0.26^{\#}$ \\
\hline
\end{tabular}

C, control senile cataract eyes; JIAUwoG, juvenile arthritis-associated anterior uveitis without glaucoma; JIAUWG, juvenile arthritis-associated anterior uveitis with glaucoma; n.a., not applicable; PC, posterior chamber; IOL, intraocular lens; CSDMARD, conventional synthetic disease-modifying anti-rheumatic drug; bDMARD, biologic disease-modifying anti-rheumatic drug.

${ }^{*}$ ANOVA, ${ }^{*} t$-test, ${ }^{+} \chi^{2}$ test/Fisher's Exact test.

The lens status of the 15 eyes with JIAUwoG were phakic, whereas only 9 of 15 eyes in JIAUwG were phakic, 3 were pseudophakic, and another 3 were aphakic.

Non-invasive laser-flare measurements did not differ between JIAUwoG (110.3 \pm 40.8 photons/ms $)$ and JIAUwG $(65.5 \pm 15.3$ photons $/ \mathrm{ms})$ patients $(P=0.26)$.

Laser-flare photometric measurement of the six JIAUwG eyes treated with prostaglandins prior to surgery $(62.9 \pm 19.8$ photons/ms) compared with the nine JIAUwoG eyes $(68.93 \pm 26.2$ photons $/ \mathrm{ms})$ revealed no differences $(P=0.85)$.

\section{Differences in the Cytokine Profile in the Anterior Chamber}

Compared with the cataract group (control), in whom SAA expression could not be detected, JIAUwoG patients showed an extensive level of SAA $(P<0.0001)$, and JIAUwG displayed an elevated level of SAA when compared with the control group, but this did not reach the level of significance $(P<0.089)$. Furthermore, SAA levels in the AC were significantly higher in JIAUwoG than in JIAUwG patients $(P<0.0116$; Figure 1).

The control group showed a slight constitutive expression of TGF $\beta-2$. The levels of TGF $\beta-2$ in the JIAUwG patients were significantly higher than in the JIAUwoG patients $(P<0.0009)$ and also compared with the control group $(P<0.0001$; Figure 1).

Compared with the cataract group, the concentration of IL-8, MMP-2, MMP-3, MMP-9, TGF $\beta-1$, TGF $\beta-3$, and TNF- $\alpha$ was significantly increased in subjects with JIAUwG or JIAUwoG. However, no significant differences in MCP-1 and MMP-1 were observed between the control group and both JIAU groups (Figure 2).

The correlation among cytokine levels are shown in Table 2. The results show that there is a correlation for the majority of 

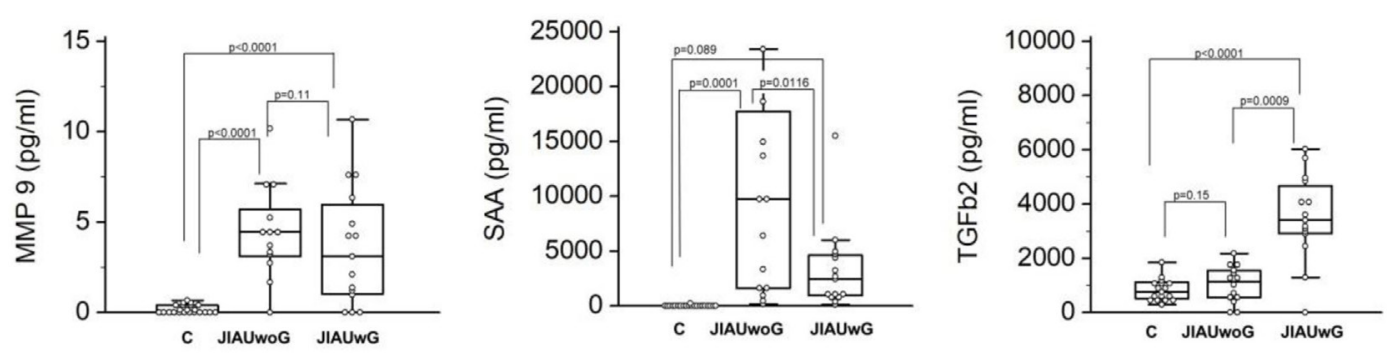

FIGURE 1 | Box plots of matrix metalloproteinases (MMP)-9, serum amyloid A (SAA), and transforming growth factor beta (TGF $\beta$ )-2 in patients with juvenile arthritis with (JIAUwG) or without glaucoma (JIAUwoG). Specimens collected from patients with senile cataract served as control. Dots represent individual values. ANOVA with Bonferroni correction (MMP-9, SAA, TGF $\beta$-2: $P<0.001$ ). Comparison between two groups by $t$-test.
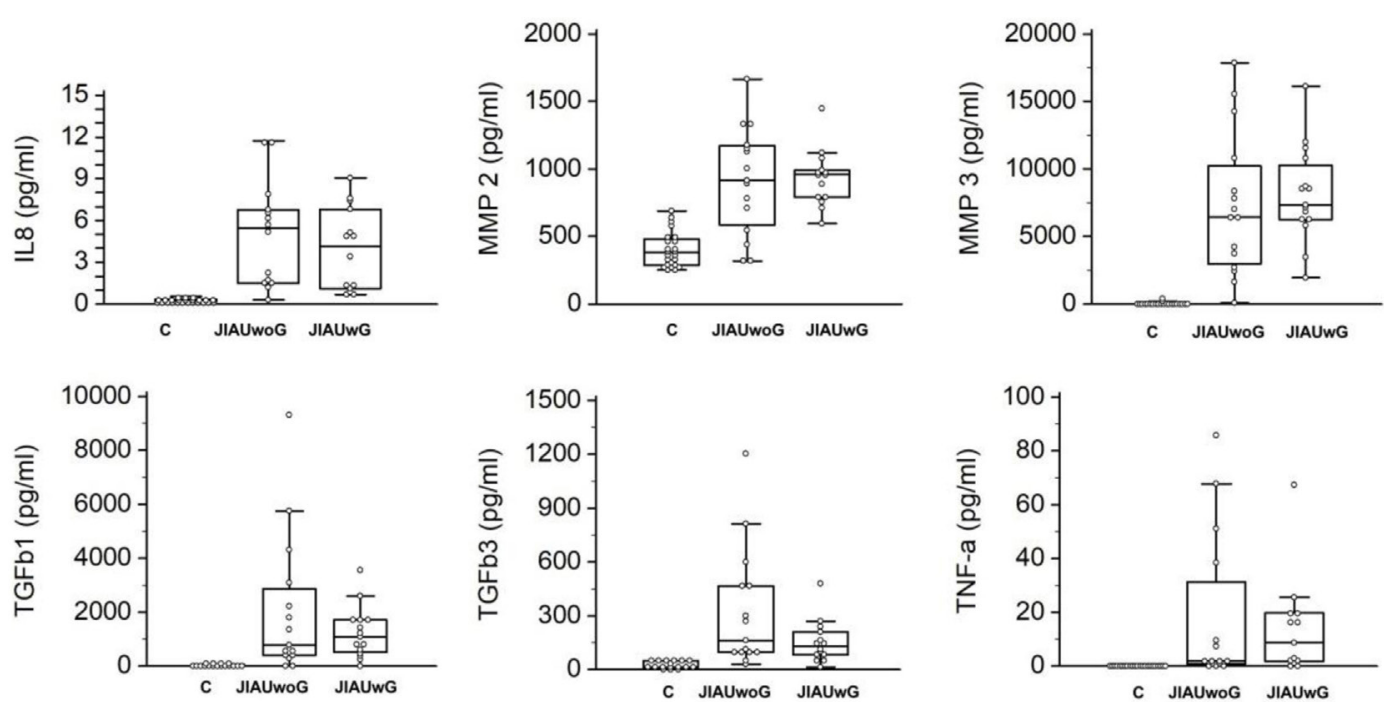

FIGURE 2 | Box plots of interleukin-8 (IL-8), matrix metalloproteinases (MMP)-2, MMP-3, transforming growth factor beta (TGF $\beta$ )-1, TGF $\beta$-3, and tumor necrosis factor-alpha $(\mathrm{TNF}-\alpha)$ in patients with juvenile idiopathic arthritis-associated uveitis with or without glaucoma. Specimens collected from patients with senile cataract served as a control. Dots represent individual values. ANOVA with Bonferroni correction $(\mathrm{IL}-8: P=0.004, \mathrm{MMP}-2: P<0.001, \mathrm{MMP}-3$ : $P<0.001, \mathrm{TGF} \beta-1$ :

$P=0.003$, TGF $\beta$-3: $P=0.002, \mathrm{TNF}-\alpha: P=0.005)$. Comparison between two groups by $t$-test.

TABLE 2 | Correlation between cytokines.

\begin{tabular}{|c|c|c|c|c|c|c|c|c|c|c|c|}
\hline$\rho / P$-value & IL-8 & MCP-1 & MMP-1 & MMP-2 & MMP-3 & MMP-9 & SAA & TGF $\beta-1$ & TGF $\beta-2$ & TGF $\beta-3$ & TNF- $\alpha$ \\
\hline IL-8 & & 0.199 & 0.828 & 0.731 & 0.827 & 0.771 & 0.725 & 0.489 & 0.307 & 0.616 & 0.695 \\
\hline MCP-1 & 0.146 & & 0.181 & 0.187 & 0.24 & 0.159 & 0.086 & 0.079 & 0.043 & 0.042 & 0.078 \\
\hline MMP-1 & $<0.0001^{*}$ & 0.1874 & & 0.694 & 0.802 & 0.736 & 0.815 & 0.536 & 0.254 & 0.610 & 0.679 \\
\hline MMP-2 & $<0.0001^{*}$ & 0.1728 & $<0.0001^{\star}$ & & 0.846 & 0.574 & 0.697 & 0.485 & 0.33 & 0.579 & 0.733 \\
\hline MMP-3 & $<0.0001^{*}$ & 0.0807 & $<0.0001^{\star}$ & $<0.0001^{*}$ & & 0.673 & 0.781 & 0.513 & 0.338 & 0.59 & 0.75 \\
\hline MMP-9 & $<0.0001^{*}$ & 0.2468 & $<0.0001^{\star}$ & $<0.0001^{*}$ & $<0.0001^{*}$ & & 0.621 & 0.499 & 0.275 & 0.544 & 0.656 \\
\hline SAA & $<0.0001^{*}$ & 0.53 & $<0.0001^{\star}$ & $<0.0001^{*}$ & $<0.0001^{*}$ & $<0.0001^{*}$ & & 0.655 & 0.298 & 0.760 & 0.652 \\
\hline TGF $\beta-1$ & $0.009^{\star}$ & 0.5923 & $0.003^{*}$ & $0.001^{\star}$ & $0.0005^{\star}$ & $0.0007^{\star}$ & $<0.0001^{\star}$ & & 0.79 & 0.846 & 0.351 \\
\hline TGF $\beta-2$ & 0.376 & 0.7714 & 0.085 & 0.0251 & 0.0218 & 0.0624 & 0.0433 & $<0.0001^{*}$ & & 0.593 & 0.261 \\
\hline TGF $\beta-3$ & $<0.0001^{*}$ & 0.7781 & $<0.0001^{\star}$ & $0.0001^{*}$ & $0.0001^{*}$ & $0.0002^{*}$ & $<0.0001^{\star}$ & $<0.0001^{*}$ & $0.0001^{*}$ & & 0.423 \\
\hline TNF- $\alpha$ & $<0.0001^{*}$ & 0.57 & $<0.0001^{\star}$ & $<0.0001^{*}$ & $<0.0001^{*}$ & $<0.0001^{*}$ & $<0.0001^{\star}$ & 0.0172 & 0.0763 & 0.0042 & \\
\hline
\end{tabular}

Significant positive correlations were calculated for the majority of cytokines. Monocyte chemoattractant protein-1 (MCP-1) and transforming growth factor beta-2 (TGF $3-2$ ) concentrations did not significantly correlate with the other cytokines. Correlation coefficient ( $\rho$ ) and P-values for each pair of cytokines were calculated by using Spearman's correlation test.

*Significant when $P<0.0045$ after Bonferroni correction for multiple comparisons.

IL-8, interleukin-8; MCP-1, monocyte chemoattractant protein-1; SAA, serum amyloid A; TGF $\beta$-1, transforming growth factor beta-1; TNF- $\alpha$, tumor necrosis factor-alpha. 
cytokines. However, MCP-1 did not correlate with the other cytokines (Table 2 ). TGF $\beta-2$ correlated only with TGF $\beta-1$ and with TGF $\beta$-3. A negative correlation was not calculated between any of the various cytokines.

\section{Correlation of Cytokines With Age, Duration of Uveitis, and Laser-Flare Values}

Correlation of cytokines in the two JIAU groups showed no significant differences with regard to age, uveitis duration, or laserflare values. Only MMP-2 was significantly elevated in patients with increased laser-flare photometric values $(P=0.0038$; Table 3).

TABLE 3 | Correlation of cytokines with age, duration of uveitis, or laser-flare values.

\begin{tabular}{|c|c|c|c|c|c|c|}
\hline & \multicolumn{2}{|c|}{$\begin{array}{c}\text { Age } \\
\text { (years) }\end{array}$} & \multicolumn{2}{|c|}{$\begin{array}{l}\text { Duration } \\
\text { of uveitis } \\
\text { (years) }\end{array}$} & \multicolumn{2}{|c|}{$\begin{array}{c}\text { Laser-flare } \\
\text { photometric values } \\
\text { (photons/ms) }\end{array}$} \\
\hline & $\begin{array}{l}\text { Correlation } \\
\text { coefficient }\end{array}$ & $P$-value & $\begin{array}{l}\text { Correlation } \\
\text { coefficient }\end{array}$ & $P$-value & $\begin{array}{l}\text { Correlation } \\
\text { coefficient }\end{array}$ & $P$-value \\
\hline IL-8 & -0.21 & 0.25 & -0.078 & 0.69 & 0.171 & 0.41 \\
\hline MCP-1 & -0.364 & 0.05 & -0.167 & 0.36 & 0.35 & 0.09 \\
\hline MMP-1 & 0.033 & 0.85 & -0.042 & 0.81 & 0.256 & 0.22 \\
\hline MMP-2 & -0.227 & 0.221 & -0.3 & 0.16 & 0.603 & $0.0038^{*}$ \\
\hline MMP-3 & 0.006 & 0.97 & -0.021 & 0.90 & 0.512 & 0.014 \\
\hline MMP-9 & -0.298 & 0.10 & -0.131 & 0.48 & 0.227 & 0.27 \\
\hline SAA & -0.063 & 0.73 & $-0,254$ & 0.17 & 0.399 & 0.056 \\
\hline TGF $\beta-1$ & 0.128 & 0.48 & 0.107 & 0.56 & 0.0038 & 0.98 \\
\hline TGF $\beta-2$ & 0.147 & 0.43 & 0.185 & 0.31 & 0.039 & 0.85 \\
\hline TGF $\beta-3$ & 0.161 & 0.93 & -0.122 & 0.51 & 0.115 & 0.58 \\
\hline TNF- $\alpha$ & -0.181 & 0.32 & -0.239 & 0.19 & 0.36 & 0.084 \\
\hline
\end{tabular}

The correlation coefficient and P-values for cytokines and age, duration of uveitis, and laser-flare values were calculated by Spearman's correlation test for JIAU eyes. The tests point to a correlation of MMP-2 with the laser-flare values.

${ }^{*} P<0.0045$ after Bonferroni correction.

IL-8, interleukin-8; MCP-1, monocyte chemoattractant protein-1; SAA, serum amyloid

A; TGF $\beta-1$, transforming growth factor beta-1; TNF- $\alpha$, tumor necrosis factor-alpha.

\section{Impact of Anti-Inflammatory or Anti- Glaucoma Medication on the Expression of Cytokines in the Anterior Chamber}

No difference in cytokine levels were observed in JIAU eyes whether patients were treated with csDMARD or prostaglandins. However, in patients treated with bDMARD, we detected significantly higher levels of MMP-1 $(P=0.027)$ and TGF $\beta-1$ $(P=0.0059$; Table 4).

\section{Risk Factors for the Development of Secondary Glaucoma}

Statistical calculation for clinical factors associated with a higher risk for glaucoma manifestation by using univariate regression analysis of age of patients, duration of uveitis, systemic treatment with conventional immunosuppressant (methotrexate, azathioprine, or cyclosporine A) or treatment with adalimumab revealed no significant influence. The presence of posterior synechiae at the time of surgery was associated with a decreased risk for secondary glaucoma development (OR 0.1025, 95\% CI $0.0168-0.6280 ; P=0.013$ ). The multivariate analysis of the above-mentioned factors also showed significant decreased OR for posterior synechiae (OR 0.1026, 95\% CI 0.0168-0.628; $P=0.0138$ ). Multivariate regression analysis for UG development including all cytokines revealed a significant correlation of TGF $\beta-2$ with UG (OR 1.0009, 95\% CI 1.0002-1.0015; $P=0.0075)$. Additional analysis of the other clinical parameters in the multivariate analysis revealed no significance.

\section{DISCUSSION}

The present study investigated the expression of pro- and antiinflammatory cytokines, chemokines, or metalloproteinases in the $\mathrm{AH}$ of patients with clinically inactive uveitis associated with JIA, both with or without glaucoma. Quiescence of uveitis disease was confirmed by clinical observation and ensured by treatment with individually adjusted anti-inflammatory medication before surgery.

TABLE 4 | Influence of csDMARD, bDMARD, or prostaglandin medication on the expression of cytokines in the anterior chamber.

\begin{tabular}{|c|c|c|c|c|c|c|c|c|c|}
\hline & \multicolumn{3}{|c|}{ csDMARD } & \multicolumn{3}{|c|}{ bDMARD } & \multicolumn{3}{|c|}{ Prostaglandins } \\
\hline & Neg & Pos & $P$-value & Neg & Pos & $P$-value & Neg & Pos & $P$-value \\
\hline Number & 4 & 26 & & 25 & 5 & & 9 & 6 & \\
\hline IL-8 & $4.2 \pm 3.2$ & $7.1 \pm 9.5$ & 0.56 & $7.3 \pm 9.6$ & $3.3 \pm 2.7$ & 0.37 & $7.4 \pm 12.7$ & $4.7 \pm 2.3$ & 0.61 \\
\hline MCP-1 & $110.1 \pm 35.5$ & $160 \pm 100$ & 0.33 & $158 \pm 97$ & $130 \pm 91$ & 0.56 & $141 \pm 72$ & $151 \pm 65$ & 0.79 \\
\hline MMP-1 & $11.2 \pm 8.5$ & $196 \pm 807$ & 0.65 & $38.4 \pm 58.9$ & 838.45 & 0.027 & $12.7 \pm 6.3$ & $30.7 \pm 41.3$ & 0.21 \\
\hline MMP-2 & $821 \pm 363$ & $984 \pm 380$ & 0.42 & $1,014 \pm 376$ & $704 \pm 280$ & 0.09 & $1,099 \pm 428$ & $875 \pm 192$ & 0.2567 \\
\hline MMP-3 & $6,211 \pm 4,074$ & $7,924 \pm 4,526$ & 0.48 & $8,210 \pm 4,525$ & $5,124 \pm 3,200$ & 0.16 & $7,779 \pm 3,522$ & $8,574 \pm 3,794$ & 0.68 \\
\hline MMP-9 & $2.3 \pm 2.1$ & $5.5 \pm 5.3$ & 0.25 & $5.5 \pm 5.3$ & $2.8 \pm 3$ & 0.28 & $4.1 \pm 3.9$ & $2.9 \pm 1.9$ & 0.54 \\
\hline SAA & $2,074 \pm 2,034$ & $7,166 \pm 7,433$ & 0.18 & $6,648 \pm 7,002$ & $5,686 \pm 8,705$ & 0.78 & $3,708 \pm 4,723$ & $2,663 \pm 2,240$ & 0.62 \\
\hline TGF $\beta-1$ & $311 \pm 250$ & $1,844 \pm 2,053$ & 0.15 & $1,213 \pm 1,261$ & $3,775 \pm 3,471$ & 0.0059 & $1,026 \pm 8,48$ & $1,511 \pm 1,087$ & 0.35 \\
\hline TGF $\beta-2$ & $1,188 \pm 1,243$ & $2,643 \pm 1,877$ & 0.14 & $2,448 \pm 1,987$ & $2,456 \pm 1,147$ & 0.99 & $3,047 \pm 1,751$ & $4,180 \pm 1,074$ & 0.18 \\
\hline TGF $\beta-3$ & $76 \pm 32$ & $289 \pm 291$ & 0.16 & $252 \pm 299$ & $301 \pm 171$ & 0.73 & $195 \pm 244$ & $201 \pm 154$ & 0.96 \\
\hline $\mathrm{TNF}-\alpha$ & $19 \pm 32$ & $22 \pm 32$ & 0.87 & $25 \pm 33$ & $5.3 \pm 3.2$ & 0.2 & $28 \pm 41$ & $21 \pm 24$ & 0.71 \\
\hline
\end{tabular}

Mean values for cytokine concentrations of eyes are depicted without or with systemic or topical treatment, CSDMARD, and bDMARD for all eyes with JIAUwG and prostaglandins. Differences in cytokine expression with or without medications were calculated by Student's t-test.

IL-8, interleukin-8; MCP-1, monocyte chemoattractant protein-1; SSA, serum amyloid A; TGF $\beta$-1, transforming growth factor beta-1; TNF- $\alpha$, tumor necrosis factor-alpha. 
We found that the concentrations of IL-8, MMP-2, MMP-3, MMP-9, TGF $\beta-1$, TGF $\beta-2$, TGF $\beta-3$, SAA, and TNF- $\alpha$ were significantly elevated in JIAU samples compared with the control group (senile cataract patients). These results show that even patients with clinically inactive JIAU receiving intensive anti-inflammatory treatment may not achieve an entirely inactive state from an immunological point of view. Instead, the AH in JIAU eyes displayed a constitutive expression of the proinflammatory cytokines IL-8 and TNF- $\alpha$. We also found an increased expression of MMP-2, MMP-3, MMP-9, TGF $\beta-1$, and TGF $\beta-3$ in eyes with JIAU, independent of the presence of glaucoma. Eyes with JIAUwG displayed increased levels of TGF $\beta-2$, while eyes with JIAUwoG showed significantly increased levels of SAA.

Elevated levels of TGF $\beta$ - 2 have previously been strongly correlated with increased outflow resistance and IOP elevation in POAG. TGF $\beta-2$ is an anti-proliferative and anti-inflammatory cytokine, which has been discussed in the context of various disorders, including glaucoma (28-30). These findings were supported by ex vivo studies using cultured AC systems derived from humans, monkeys, or pigs (31-33). TGF $\beta-2$ was shown to markedly elevate IOP, possibly via a mechanism involving increased expression and deposition of extracellular material within the TM (31). An increased TGF $\beta-2$ protein content in the $\mathrm{AH}$ in vivo also correlated with elevated IOP in rodents (34-37). TGF $\beta$-2 induces increased ECM synthesis in TM cells that is largely regulated by Smad3-mediated signal mechanisms $(35,38,39)$.

Increased SAA concentrations in the AC of eyes with glaucoma have been found previously, too. Here, the expression of SAA2 was increased in TM tissues from donors with glaucoma. Furthermore, treatment of cultured human TM cells with recombinant SAA affected upregulation of IL-8 and increased IOP in the human ocular perfusion organ culture (40).

In a recent study, various inflammatory cytokines in the $\mathrm{AH}$ of patients with POAG, exfoliation glaucoma (EXG) and senile cataract were determined. Herein, increased TGF $\beta-1$, IL-8, and SAA levels were found in POAG and EXG when compared with the cataract control group. IL- 6 was decreased in the POAG group. The levels of TGF $\beta-1$, IL-8, and SAA correlated positively with each other, with IOP, and the number of glaucoma medications. The authors concluded that TGF $\beta-1$, IL-8, and SAA have critical roles in IOP elevations in patients with POAG (20). Another group found the levels of IL-8, TGF $\beta-1$, TNF- $\alpha$, and SAA to be significantly increased in POAG and pseudoexfoliation glaucoma (PEXG) patients compared with controls, while levels of IL-6 were significantly decreased in both glaucoma groups compared with controls (41).

Moreover, previous studies of rheumatoid arthritis have shown that SAA in the serum was strongly associated with disease activity, but also with the risk of cardiovascular and renal involvement and could, therefore, serve as a marker to help identify patients with persistent inflammation and at risk of extra-articular complications (42). Similar results were found in patients with ankylosing spondylitis (43). C-reactive protein (CRP) and SAA were shown to be valuable biomarkers of infectious or inflammatory processes (44).
It has been shown previously that SAA may attract migrating phagocytes to the site of inflammation, serve as an agonist for toll-like receptor 4 , activate nuclear factor NF- $\mathrm{kB}$, and induce expression of both inflammatory cytokines and M2 macrophage markers and to influence polymorphonuclear neutrophils (PMN) by inhibiting apoptosis and enhancing efferocytosis $(45,46)$. We conclude based on the known activities that SAA is expressed locally in chronic inflammatory conditions such as JIAU and may act via diverse proinflammatory functional mechanisms to regulate homeostasis in the AC of eyes with JIAU and does not support development of glaucoma.

However, inflammation responses in the eye must be downregulated, for example, by anti-inflammatory cytokines, to minimize tissue damage in the eye. It has been shown previously that TGF $\beta-2$ may influence the levels of SAA. A previous study has shown that IL-10-/- mice that develop a form of inflammatory bowel disease (a model for Crohn's disease) gained more weight and developed lower pathological scores, lower TNF- $\alpha$ concentrations, and lower SAA content when mice were fed a TGF $\beta$-2-containing diet (47). We, therefore, assume that there is a reciprocal relationship between SAA and TGF $\beta-2$ in the AH of JIAU patients. In some of the JIAU patients, high TGF $\beta-2$ levels could be produced to control SAA, but this process might promote the development of glaucoma.

Some of the patients with JIAUwG received medication with Latanoprost or Bimatoprost to treat elevated IOP. Previous studies have shown that topical treatment with Latanoprost decreased levels of TGF $\beta-1$, MMP-2, and tissue inhibitor of metalloproteinases-2 in patients suffering from PEXG (48). In a TM in vitro system, Latanoprost decreased collagen accumulation but promoted a contractile phenotype in TM cells that could modulate the conventional outflow pathway (49). Another study has shown that long-term treatment with Latanoprost could be associated with enhanced Tenon's capsule fibroblast proliferation and increased expression of TGF $\beta$ and MMPs, probably promoting the scarring of the filtering blebs following glaucoma-filtering surgery (50). An ELISA assay in patients with glaucoma and prostaglandin therapy revealed no differences in MMP-2 and -9 levels compared with control eyes (51), nor did we find an influence of prostaglandin medication on the expression of cytokines, chemokines, or MMPs in the AC. Therefore, we assume that the modulated cytokine levels in the $\mathrm{AH}$ are primarily related to the increased IOP values or development of glaucoma rather than to the prostaglandin/ Latanoprost medication.

No information has been published about the impact of csDMARD on intraocular cytokine concentrations. However, our data show that treatment with csDMARD did not significantly alter cytokine concentrations in the AH. In contrast, our data demonstrate that there was a significant difference in the expression of MMP-1 or TGF $\beta-1$ after treatment with bDMARD. An explanation could be that bDMARD are favored in patients with a particularly severe JIAU disease course with or without glaucoma. However, our results imply that the use of bDMARD modulated the local immune response of the patients.

Tumor necrosis factor-alpha is a proinflammatory cytokine with pleiotrophic effects on various cell types. Recent results 
suggest that the TNF- $\alpha$ neutralizing function dictates not only the success of anti-inflammatory treatment, but also other biological effects. Anti-TNF- $\alpha$ medications are increasingly being used to treat JIAU (52). However, the TNF-targeting molecules available differ in their function to induce complement-dependent cytotoxicity or antibody-dependent cellular cytotoxicity and to trigger full transmembrane TNF- $\alpha$ signaling, which may lead to TGF $\beta$ synthesis. It has been described previously that reverse signaling of transmembrane TNF- $\alpha$ may lead to TGF $\beta$ production in macrophages, and anti-TNF- $\alpha$ agents selectively trigger this pathway (53).

In some diseases, e.g., rheumatoid arthritis, TGF $\beta$ signaling is enhanced and seems to play a proinflammatory rather than an anti-inflammatory role. TGF $\beta$ - 1 promoted the expression of proinflammatory cytokines and metalloproteinases (54), by acting as a potent chemoattractant for PMN (55), by activating the expression of chemokines (56), and by promoting angiogenesis and synovial cell proliferation $(53,57)$.

Recent studies have shown that pharmacological blockade of IL- 6 by a humanized anti-IL- 6 receptor antibody is beneficial in patients with rheumatoid arthritis and JIA, suggesting that IL-6 might be an essential key cytokine in these diseases. IL- 6 was shown to be involved in the induction of Th17 cell stimulation with TGF $\beta$. Together with TNF- $\alpha$ and IL-1, IL-6 induces CRP or SAA signaling. Indeed, IL- 6 was among those cytokines previously detected in the AH of JIAU patients (58), and while blocking TNF- $\alpha$ reduced acute phase proteins (CRP, SAA), IL- 6 blockade additionally induced normalization of these proteins $(53,59)$.

In conclusion, the results of the current study show that pro- and anti-inflammatory cytokine, chemokine, or metalloproteinase levels are increased in clinically inactive JIAU eyes, suggesting that in these eyes disease is seemingly not inactive

\section{REFERENCES}

1. Heiligenhaus A, Heinz C, Edelsten C, Kotaniemi K, Minden K. Review for disease of the year: epidemiology of juvenile idiopathic arthritis and its associated uveitis: the probable risk factors. Ocul Immunol Inflamm (2013) 21(3):180-91. doi:10.3109/09273948.2013.791701

2. Dana MR, Merayo-Lloves J, Schaumberg DA, Foster CS. Visual outcomes prognosticators in juvenile rheumatoid arthritis-associated uveitis. Ophthalmology (1997) 104(2):236-44. doi:10.1016/S0161-6420(97)30329-7

3. Sabri K, Saurenmann RK, Silverman ED, Levin AV. Course, complications, and outcome of juvenile arthritis-related uveitis. JAAPOS (2008) 12(6): 539-45. doi:10.1016/j.jaapos.2008.03.007

4. Siddique SS, Suelves AM, Baheti U, Foster CS. Glaucoma and uveitis. Surv Ophthalmol (2013) 58(1):1-10. doi:10.1016/j.survophthal.2012.04.006

5. Sijssens KM, Rothova A, Berendschot TT, de Boer JH. Ocular hypertension and secondary glaucoma in children with uveitis. Ophthalmology (2006) 113(5):859. doi:10.1016/j.ophtha.2006.01.043

6. Heinz C, Schumacher C, Roesel M, Heiligenhaus A. Elevated intraocular pressure in uveitis associated with juvenile idiopathic arthritis-associated uveitis, often detected after achieving inactivity. Br JOphthalmol (2012) 96(1):140-1. doi:10.1136/bjophthalmol-2011-300731

7. Heinz C, Koch JM, Zurek-Imhoff B, Heiligenhaus A. Prevalence of uveitic secondary glaucoma and success of nonsurgical treatment in adults and children in a tertiary referral center. Ocul Immunol Inflamm (2009) 17(4):243-8. doi:10.1080/09273940902913035

8. Tektas OY, Heinz C, Heiligenhaus A, Hammer CM, Luetjen-Drecoll E. Morphological changes of trabeculectomy specimens in different kinds of from an immunological point of view and that the eyes show a cytokine profile typical of chronic inflammation. The pathogenetic process for the development of glaucoma in some of the JIAU patients may be related to the severity of ocular inflammation, the use of corticosteroids, and complications such as posterior synechiae, damage of anterior chamber angle or to the TM. We therefore conclude that the etiologic mechanisms involved are multifactorial. However, the significantly increased levels of SAA in JIAUwoG and of TGF $\beta$-2 in JIAUwG suggest that the cytokines could play important roles in modulating IOP. Previous studies have found that SAA may induce IL-8 production of TM. TGF $\beta-2$ has been shown to decrease SAA and TNF- $\alpha$ and to regulate ECM synthesis and remodeling $(40,47)$. These molecules may be relevant for studying the pathologic mechanism of IOP elevation in secondary glaucoma in the future.

\section{ETHICS STATEMENT}

The study design complies with the standards put forth by the Declaration of Helsinki. The study was approved by the local ethics committee. All subjects provided written informed consent for $\mathrm{AH}$ collection during independently planned surgery. For underaged JIAU patients, written informed consent was obtained from the patients' parents.

\section{AUTHOR CONTRIBUTIONS}

$\mathrm{DB}, \mathrm{MK}$, and $\mathrm{CH}$ designed the study and wrote the manuscript. $\mathrm{DB}, \mathrm{MK}, \mathrm{PM}, \mathrm{BK}, \mathrm{KW}$, and $\mathrm{CH}$ performed the experiments and analyzed the data. $\mathrm{KW}, \mathrm{JK}, \mathrm{AH}$, and $\mathrm{CH}$ performed the eye surgery, collected the aqueous humor, and provided clinical data. All authors approved the final version of the manuscript.

uveitic glaucoma. Curr Eye Res (2011) 36(5):442-8. doi:10.3109/02713683. 2011.566409

9. Moorthy RS, Mermoud A, Baerveldt G, Minckler DS, Lee PP, Rao NA. Glaucoma associated with uveitis. Surv Ophthalmol (1997) 41(5):361-94. doi:10.1016/S0039-6257(97)00006-4

10. Toris CB, Pederson JE. Aqueous humor dynamics in experimental iridocyclitis. Invest Ophthalmol Vis Sci (1987) 28(3):477-81.

11. Zhang JM, An J. Cytokines, inflammation, and pain. Int Anesthesiol Clin (2007) 45(2):27-37. doi:10.1097/AIA.0b013e318034194e

12. Lee IT, Lin CC, Wu YC, Yang CM. TNF-alpha induces matrix metalloproteinase9 expression in A549 cells: role of TNFR1/TRAF2/PKCalpha-dependent signaling pathways. J Cell Physiol (2010) 224(2):454-64. doi:10.1002/jcp.22142

13. Letterio JJ, Roberts AB. TGF-beta: a critical modulator of immune cell function. Clin Immunol Immunopathol (1997) 84(3):244-50. doi:10.1006/clin. 1997.4409

14. Roberts AB, Flanders KC, Kondaiah P, Thompson NL, Van ObberghenSchilling E, Wakefield L, et al. Transforming growth factor beta: biochemistry and roles in embryogenesis, tissue repair and remodeling, and carcinogenesis. Recent Prog Horm Res (1988) 44:157-97.

15. Choi JA, Kim JE, Noh SJ, Kyoung Kim E, Park CK, Paik SY. Enhanced cytomegalovirus infection in human trabecular meshwork cells and its implication in glaucoma pathogenesis. Sci Rep (2017) 7:43349. doi:10.1038/ srep43349

16. Curnow SJ, Falciani F, Durrani OM, Cheung CM, Ross EJ, Wloka K, et al. Multiplex bead immunoassay analysis of aqueous humor reveals distinct cytokine profiles in uveitis. Invest Ophthalmol Vis Sci (2005) 46(11):4251-9. doi:10.1167/iovs.05-0444 
17. Ooi KG, Galatowicz G, Towler HM, Lightman SL, Calder VL. Multiplex cytokine detection versus ELISA for aqueous humor: IL-5, IL-10, and IFNgamma profiles in uveitis. Invest Ophthalmol Vis Sci (2006) 47(1):272-7. doi:10.1167/iovs.05-0790

18. Takase H, Futagami Y, Yoshida T, Kamoi K, Sugita S, Imai Y, et al. Cytokine profile in aqueous humor and sera of patients with infectious or noninfectious uveitis. Invest Ophthalmol Vis Sci (2006) 47(4):1557-61. doi:10.1167/ iovs.05-0836

19. Kaneda S, Miyazaki D, Sasaki S, Yakura K, Terasaka Y, Miyake K, et al. Multivariate analyses of inflammatory cytokines in eyes with branch retinal vein occlusion: relationships to bevacizumab treatment. Invest Ophthalmol Vis Sci (2011) 52(6):2982-8. doi:10.1167/iovs.10-6299

20. Takai Y, Tanito M, Ohira A. Multiplex cytokine analysis of aqueous humor in eyes with primary open-angle glaucoma, exfoliation glaucoma, and cataract. Invest Ophthalmol Vis Sci (2012) 53(1):241-7. doi:10.1167/ iovs.11-8434

21. Bloch-Michel E, Nussenblatt RB. International Uveitis Study Group recommendations for the evaluation of intraocular inflammatory disease. Am J Ophthalmol (1987) 103(2):234-5. doi:10.1016/S0002-9394(14)74235-7

22. Jabs DA, Nussenblatt RB, Rosenbaum JT; Standardization of Uveitis Nomenclature Working Group. Standardization of uveitis nomenclature for reporting clinical data. Results of the First International Workshop. Am J Ophthalmol (2005) 140(3):509-16. doi:10.1016/j.ajo.2005.03.057

23. Gonzales CA, Ladas JG, Davis JL, Feuer WJ, Holland GN. Relationships between laser flare photometry values and complications of uveitis. Arch Ophthalmol (2001) 119(12):1763-9. doi:10.1001/archopht.119.12.1763

24. Ladas JG, Wheeler NC, Morhun PJ, Rimmer SO, Holland GN. Laser flare-cell photometry: methodology and clinical applications. Surv Ophthalmol (2005) 50(1):27-47. doi:10.1016/j.survophthal.2004.10.004

25. Tappeiner C, Heinz C, Roesel M, Heiligenhaus A. Elevated laser flare values correlate with complicated course of anterior uveitis in patients with juvenile idiopathic arthritis. Acta Ophthalmol (2011) 89(6):e521-7. doi:10.1111/j.1755-3768.2011.02162.x

26. Heiligenhaus A, Michels H, Schumacher C, Kopp I, Neudorf U, Niehues T, et al. Evidence-based, interdisciplinary guidelines for anti-inflammatory treatment of uveitis associated with juvenile idiopathic arthritis. Rheumatol Int (2012) 32(5):1121-33. doi:10.1007/s00296-011-2126-1

27. Petty RE, Southwood TR, Manners P, Baum J, Glass DN, Goldenberg J, et al. International league of associations for rheumatology classification of juvenile idiopathic arthritis: second revision, Edmonton, 2001. J Rheumatol (2004) 31(2):390-2.

28. Inatani M, Tanihara H, Katsuta H, Honjo M, Kido N, Honda Y. Transforming growth factor-beta 2 levels in aqueous humor of glaucomatous eyes. Graefes Arch Clin Exp Ophthalmol (2001) 239(2):109-13. doi:10.1007/ s004170000241

29. Picht G, Welge-Luessen U, Grehn F, Lutjen-Drecoll E. Transforming growth factor beta 2 levels in the aqueous humor in different types of glaucoma and the relation to filtering bleb development. Graefes Arch Clin Exp Ophthalmol (2001) 239(3):199-207. doi:10.1007/s004170000252

30. Min SH, Lee TI, Chung YS, Kim HK. Transforming growth factor-beta levels in human aqueous humor of glaucomatous, diabetic and uveitic eyes. Korean J Ophthalmol (2006) 20(3):162-5. doi:10.3341/kjo.2006. 20.3.162

31. Gottanka J, Chan D, Eichhorn M, Lutjen-Drecoll E, Ethier CR. Effects of TGF-beta2 in perfused human eyes. Invest Ophthalmol Vis Sci (2004) 45(1): 153-8. doi:10.1167/iovs.03-0796

32. Bachmann B, Birke M, Kook D, Eichhorn M, Lutjen-Drecoll E. Ultrastructural and biochemical evaluation of the porcine anterior chamber perfusion model. Invest Ophthalmol Vis Sci (2006) 47(5):2011-20. doi:10.1167/ iovs.05-1393

33. Bhattacharya SK, Gabelt BT, Ruiz J, Picciani R, Kaufman PL. Cochlin expression in anterior segment organ culture models after TGFbeta2 treatment. Invest Ophthalmol Vis Sci (2009) 50(2):551-9. doi:10.1167/iovs. 08-2632

34. Robertson JV, Golesic E, Gauldie J, West-Mays JA. Ocular gene transfer of active TGF-beta induces changes in anterior segment morphology and elevated IOP in rats. Invest Ophthalmol Vis Sci (2010) 51(1):308-18. doi:10.1167/ iovs.09-3380
35. McDowell CM, Tebow HE, Wordinger RJ, Clark AF. Smad3 is necessary for transforming growth factor-beta2 induced ocular hypertension in mice. Exp Eye Res (2013) 116:419-23. doi:10.1016/j.exer.2013.10.017

36. Swaminathan SS, Oh DJ, Kang MH, Shepard AR, Pang IH, Rhee DJ. TGFbeta2-mediated ocular hypertension is attenuated in SPARC-null mice. Invest Ophthalmol Vis Sci (2014) 55(7):4084-97. doi:10.1167/iovs.13-12463

37. Hill LJ, Mead B, Blanch RJ, Ahmed Z, De Cogan F, Morgan-Warren PJ, et al. Decorin reduces intraocular pressure and retinal ganglion cell loss in rodents through fibrolysis of the scarred trabecular meshwork. Invest Ophthalmol Vis Sci (2015) 56(6):3743-57. doi:10.1167/iovs.14-15622

38. Fuchshofer R, Stephan DA, Russell P, Tamm ER. Gene expression profiling of TGFbeta2- and/or BMP7-treated trabecular meshwork cells: identification of Smad7 as a critical inhibitor of TGF-beta2 signaling. Exp Eye Res (2009) 88(6):1020-32. doi:10.1016/j.exer.2009.01.002

39. Tovar-Vidales T, Clark AF, Wordinger RJ. Transforming growth factorbeta2 utilizes the canonical Smad-signaling pathway to regulate tissue transglutaminase expression in human trabecular meshwork cells. Exp Eye Res (2011) 93(4):442-51. doi:10.1016/j.exer.2011.06.011

40. Wang WH, McNatt LG, Pang IH, Hellberg PE, Fingert JH, McCartney MD, et al. Increased expression of serum amyloid A in glaucoma and its effect on intraocular pressure. Invest Ophthalmol Vis Sci (2008) 49(5):1916-23. doi:10.1167/iovs.07-1104

41. Khalef N, Labib H, Helmy H, El Hamid MA, Moemen L, Fahmy I. Levels of cytokines in the aqueous humor of eyes with primary open angle glaucoma, pseudoexfoliation glaucoma and cataract. Electron Phys (2017) 9(2):3833-7. doi:10.19082/3833

42. Targonska-Stepniak B, Majdan M. Serum amyloid A as a marker of persistent inflammation and an indicator of cardiovascular and renal involvement in patients with rheumatoid arthritis. Mediators Inflamm (2014) 2014:793628. doi:10.1155/2014/793628

43. Jung SY, Park MC, Park YB, Lee SK. Serum amyloid a as a useful indicator of disease activity in patients with ankylosing spondylitis. Yonsei Med J (2007) 48(2):218-24. doi:10.3349/ymj.2007.48.2.218

44. dos Anjos BL, Grotto HZ. Evaluation of C-reactive protein and serum amyloid A in the detection of inflammatory and infectious diseases in children. Clin Chem Lab Med (2010) 48(4):493-9. doi:10.1515/CCLM.2010.110

45. Tamamoto T, Ohno K, Goto-Koshino Y, Tsujimoto H. Feline serum amyloid A protein as an endogenous Toll-like receptor 4 agonist. Vet Immunol Immunopathol (2013) 155(3):190-6. doi:10.1016/j.vetimm.2013.06.010

46. Ye RD, Sun L. Emerging functions of serum amyloid A in inflammation. J Leukoc Biol (2015) 98(6):923-9. doi:10.1189/jlb.3VMR0315-080R

47. Oz HS, Ray M, Chen TS, McClain CJ. Efficacy of a transforming growth factor beta 2 containing nutritional support formula in a murine model of inflammatory bowel disease. J Am Coll Nutr (2004) 23(3):220-6. doi:10.1080/ 07315724.2004.10719364

48. Konstas AG, Koliakos GG, Karabatsas CH, Liakos P, Schlotzer-Schrehardt U, Georgiadis N, et al. Latanoprost therapy reduces the levels of TGF beta 1 and gelatinases in the aqueous humour of patients with exfoliative glaucoma. Exp Eye Res (2006) 82(2):319-22. doi:10.1016/j.exer.2005.07.004

49. Kalouche G, Beguier F, Bakria M, Melik-Parsadaniantz S, Leriche C, Debeir T, et al. Activation of prostaglandin FP and EP2 receptors differently modulates myofibroblast transition in a model of adult primary human trabecular meshwork cells. Invest Ophthalmol Vis Sci (2016) 57(4):1816-25. doi:10.1167/ iovs.15-17693

50. Leng F, Liu P, Li H, Zhang J. Long-term topical antiglaucoma medications cause enhanced Tenon's capsule fibroblast proliferation and abnormal TGF-beta and MMP expressions: potential effects on glaucoma filtering surgery. Curr Eye Res (2011) 36(4):301-9. doi:10.3109/02713683.2010. 547648

51. Pradhan ZS, Dalvi RA, Lai T, Kranemann C, Boyd S, Birt CM. Prostaglandin agonist effect on matrix metalloproteinase aqueous levels in glaucoma patients. Can J Ophthalmol (2015) 50(1):6-10. doi:10.1016/j.jcjo. 2014.10.006

52. Tappeiner C, Schenck S, Niewerth M, Heiligenhaus A, Minden K, Klotsche J. Impact of antiinflammatory treatment on the onset of uveitis in juvenile idiopathic arthritis: longitudinal analysis from a nationwide pediatric rheumatology database. Arthritis Care Res (Hoboken) (2016) 68(1):46-54. doi:10.1002/ acr.22649 
53. Szondy Z, Pallai A. Transmembrane TNF-alpha reverse signaling leading to TGF-beta production is selectively activated by TNF targeting molecules: therapeutic implications. Pharmacol Res (2017) 115:124-32. doi:10.1016/j. phrs.2016.11.025

54. Cheon H, Yu SJ, Yoo DH, Chae IJ, Song GG, Sohn J. Increased expression of pro-inflammatory cytokines and metalloproteinase- 1 by TGF-betal in synovial fibroblasts from rheumatoid arthritis and normal individuals. Clin Exp Immunol (2002) 127(3):547-52. doi:10.1046/j.1365-2249.2002.01785.x

55. Fava RA, Olsen NJ, Postlethwaite AE, Broadley KN, Davidson JM, Nanney LB, et al. Transforming growth factor beta 1 (TGF-beta 1) induced neutrophil recruitment to synovial tissues: implications for TGF-beta-driven synovial inflammation and hyperplasia. J Exp Med (1991) 173(5):1121-32. doi:10.1084/ jem.173.5.1121

56. Loetscher P, Moser B. Homing chemokines in rheumatoid arthritis. Arthritis Res (2002) 4(4):233-6. doi:10.1186/ar412

57. Muller-Ladner U, Ospelt C, Gay S, Distler O, Pap T. Cells of the synovium in rheumatoid arthritis. Synovial fibroblasts. Arthritis Res Ther (2007) 9(6): 223. doi:10.1186/ar2337

58. Sijssens KM, Rijkers GT, Rothova A, Stilma JS, Schellekens PA, de Boer JH. Cytokines, chemokines and soluble adhesion molecules in aqueous humor of children with uveitis. Exp Eye Res (2007) 85(4):443-9. doi:10.1016/j. exer.2007.06.011

59. Yoshizaki K. [New therapeutic strategy for autoimmune and chronic inflammatory disease based on clinical results using IL-6 blocking therapy with a humanized anti-IL-6 receptor antibody]. Yakugaku Zasshi (2009) 129(6):667-74. doi:10.1248/yakushi.129.667

Conflict of Interest Statement: The authors declare that the research was conducted in the absence of any commercial or financial relationship that could be construed as a potential conflict of interest.

Copyright (c) 2018 Bauer, Kasper, Walscheid, Koch, Müther, Kirchhof, Heiligenhaus and Heinz. This is an open-access article distributed under the terms of the Creative Commons Attribution License (CC BY). The use, distribution or reproduction in other forums is permitted, provided the original author(s) and the copyright owner are credited and that the original publication in this journal is cited, in accordance with accepted academic practice. No use, distribution or reproduction is permitted which does not comply with these terms. 